\title{
Strengthened Adaptive Capacity Using Interactive Approach Integrative Framework: Science Community with Civil Society
}

\author{
${ }^{1}$ Hala Abayazid, ${ }^{2}$ Ibrahim El-Shinnawy
}

\begin{abstract}
Climate change phenomenon brought major uncertainty and stresses to environmental resources. In particular, the coastal ecosystems are customarily considered one of the most complex systems to sustain, experiencing continuous fluctuation and changes by nature, and climate change will only add to this complexity. That fact underscores the necessity of finding effective adaptive methodology governing the coastal system vulnerability while facing climate change impact. This paper argues that sustainability of coastal zones must employ an adaptive policy that incorporates multi-disciplinary regulatory mechanism along with community inputs for better decision support. Through a case study application in a coastal zone North-Eastern of the Nile Delta of Egypt, the hypothesis of having a multi-disciplinary adaptation plan cutting across major sectors, while applying an interactive framework that ensure involvement of communities and stakeholders all along the planning process, proved to lead to strengthened resilience of coastal developments facing climate change impact.
\end{abstract}

Keywords: coastal system; climate change; sustainability; adaptive policy

\section{Introduction}

Changes in climate in terms of temperatures, precipitation and sea levels are having immediate hydrological alterations that, in turn, have consequences on environmental and socio-economic state. Vulnerability to these potential impacts depends on variations in the capabilities to adapt to and prepare for the changes. With challenges facing policy makers and practitioners concerned with climate change worldwide, this research presents an integrated approach for adaptive capacity assessment to projected climate change and sea level rise in an active coastal area. Adaptive capacity is typically evaluated ecologically with academic perspective, in one hand, and socially in the other. In this research study an interactive methodology has been employed so that adaptive behavior is detected and adjusted during the research process before concluding the final adaptation policy. Various dimensions are dealt with simultaneously, hydrological, environmental, socioeconomic and physical responses to climate changes.

Earlier studies conducted within the framework of efforts for climate change impact assessment have concluded potential system malfunctionality with reference to predicted Sea Level Rise scenarios. Results showed prospective alterations in terms of advancement of shoreline inland and inundation threats, salinity intrusion into coastal aquifer and raise in groundwater level, and excess discharges into the agricultural drainage network.

The paper first presents a review of formal definitions for the adaptive capacity in literature to be employed as reference in analysis. On basis of the study findings, this research highlights certain considerations in assessing adaptive capacity of coastal zone for the area under consideration in the delta.

The paper is concluding with recommended measures to be considered for stronger adaptive capacity to climate change. In this context, basic measures should include, beside the physical adaptation measures, preparing civil society, decision makers as well as scientific community with required knowledge and advanced equipment. Most of all, flexibility is an important ingredient to be added to policy planning in order to face the wide range of predictions and continuous alteration in conditions.

\section{Background}

Sea Level Rise has been recognized as early as in the mid-19th century. However, during the 20th century, sea level rose about $15-20$ centimeters (roughly 1.5 to $2.0 \mathrm{~mm} / \mathrm{year}$ ), with the rate at the end of the century greater than over the early part of the century. Recent increase of rate is depicted to jump to about 3.1 $\mathrm{mm} / \mathrm{year}$, which is significantly higher than the average rate for the 20th century (Douglas, 1997 and IPCC, 2007) Alarmed with findings of the worst scenario "A1F1" stated in the Intergovernmental Panel on Climate Change (IPCC) Fourth Assessment Report and the First National Communication which has reported that over $30 \%$ (about third) of the Delta area would be inundated by year 2100 as a result of climate change and sea level rise, extensive studies to assess actual vulnerability degree of the Nile Delta coastal zone have been conducted. While results of the Coastal Research Institute (CoRI) downscaling in the Second National Communication on climate change (SNC) assured different findings and less threat than early findings, yet concerns at certain delta coastal areas have still been valid. 
The Nile Delta of Egypt has a distinctive importance nation-wide socially, economically as well as environmentally, with its fertile agricultural lands, active industrial facilities and tourism resorts, fishing activities as well as high populations and expanded infrastructure. Meanwhile, certain regions in the coastal zone of the Nile delta are recognized as a vulnerable region for Sea Level Rise threats, including the NorthEastern part (Figure 1). Within the framework of a multi-disciplinary project that addresses the concept of sustainable management of the delta coastal zone in face of climate change challenges, bio-physical as well as socio-economic aspects of potential impact of climate changes and sea level rise in near future have been covered, simultaneously. The scope of this paper is to present main aspects of the interactive approach for better adaptive capacity.

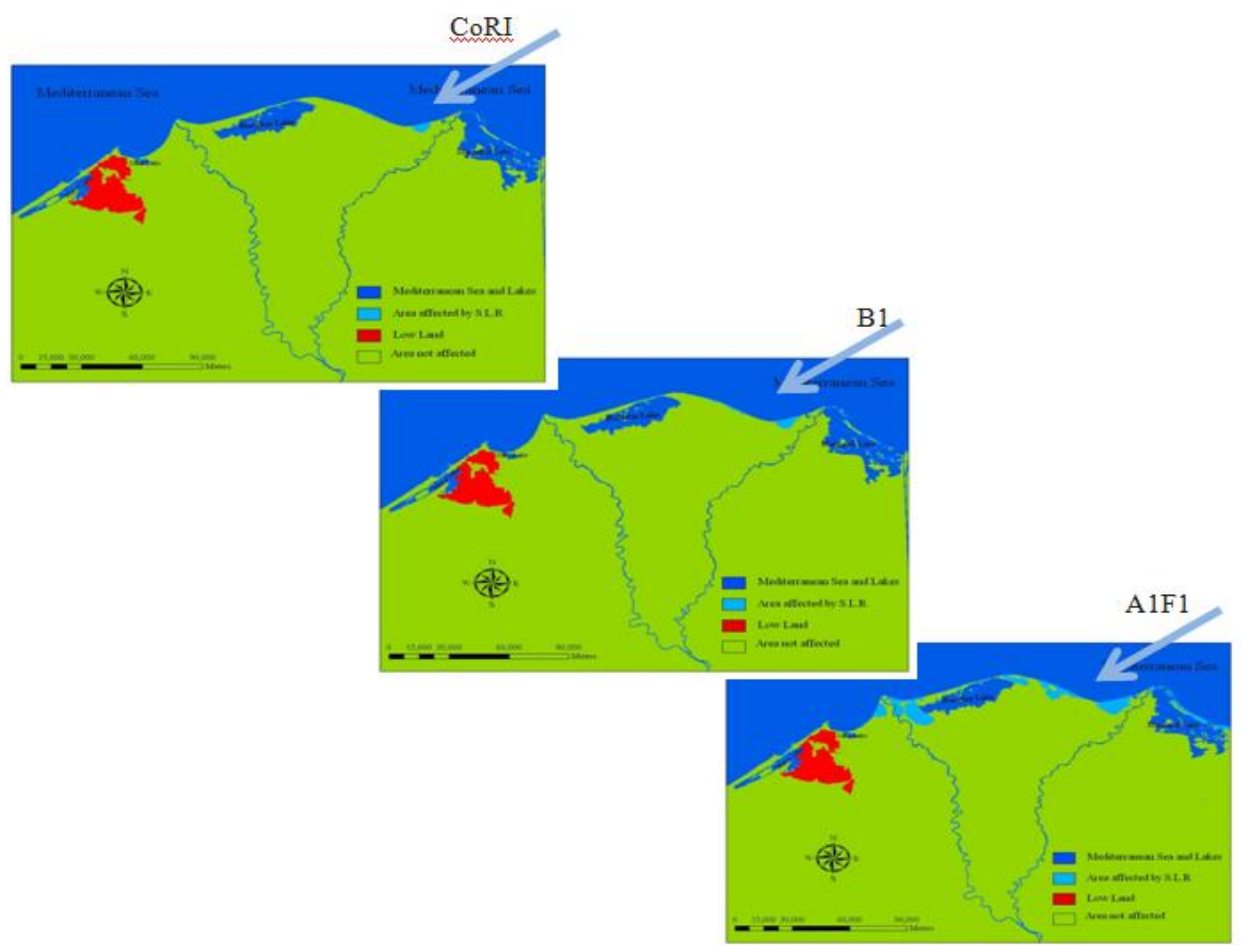

Figure 1: Projected Impacts of Sea Level Rise in 2100 with CoRI, B1 and A1F1 Scenarios

\section{Literature Review}

Adaptive capacity has been presented in literature with several phrasing, yet mainly sharing the basic concept. In principal, it is a measure of preparedness or ability to adjust with changes as needed. For example, adaptive capacity has been identified as the capacity of a system to adapt if the environment where the system exists is changing. Also, the adaptive capacity has been described as the resilience capability of systems in face of alarming conditions that give ecological and social systems the ability to reconfigure themselves with minimum loss of function.

Adaptive capacity to climate change is defined in the Fourth Assessment Report of the Intergovernmental Panel on Climate Change as the ability or potential of a system to respond successfully to climate variability and change, and include adjustments in behavior, resources and technologies (IPCC, 2007). Adaptability has also been defined by the Resilience Alliance organization as the capacity of actors in a system to manage resilience, either by moving the system toward or away from a threshold that would fundamentally alter the properties of the system, (Available at: http://www.resalliance.org/). Another interpretation to the concept of system coping capacity has been presented by the Millennium Ecosystem Assessment as the general ability of institutions, systems, and individuals to adjust to potential damage, to take advantage of opportunities, or to cope with the consequences (Source: http://www.millenniumassessment.org/). Earlier analyses by scholars have concluded that the existence of institutions and networks for learning and storing knowledge creates flexibility in problem solving and balance power among interest groups, which play an important role in adaptive capacity.

Adaptive behavior is a type of behavior that is used to adjust to another type of behavior or situation. Adaptations are commonly defined as evolved solutions to recurrent environmental problems of survival and reproduction (Buss and Greiling, 1999). With ecological sense, an adaptive behavior is a behavior which contributes directly or indirectly to an individual's survival or reproductive success and is thus subject to the forces of natural selection (Starr and Taggart, 2004) 
In climate change studies, adaptive capacity has a comparative sense with vulnerability status. Vulnerability is considered a function of magnitude/ rate of change to which a system is exposed versus sensitivity and adaptive capacity of that system. By definition, Vulnerability is the degree to which a system is susceptible to, and unable to cope with, adverse effects of climate change, including climate variability and extremes (IPCC, 2007).

\section{Methodology}

The proposed adaptive capacity assessment takes an integrative nature that, while emphasis developing of intercultural communication skills among stakeholders, officials and local societies in one hand, encourage active interaction between researchers with sophisticated scientific background and communities with different education levels so that all would meet in a common point of understanding.

\section{Balancing functionality equation: climate threats versus preparedness to adapt}

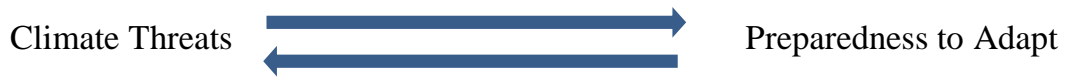

Aspects such as non-stoppable growing population and advancing pace in development process would, undoubtfully, affect and be affected in many ways by adaptive capacity to climate change impact. Meanwhile, models have a wide range of predictions that are regularly updated. These factors make the equation balance change all the time. In addition, illiteracy percentage and limitation in financial resources are having significant weights to consider in adaptability equation. Educated/aware people who are used to refer to logic and reasoning are expected to have different adaptive capacity than illiterate community. Also, availability of economic resources would support stronger adaptive capacity. Following are three key equations to be balanced when considering adaptive capacity of a functional coastal system in face of climate change impact and Sea Level Rise.

\section{Hydro-physical equation}

Threats: sea water intrusion into coastal aquifer, increased salinity concentration, Groundwater elevated level, agricultural drainage system malfunctionality, coastal inundation and loss of lands.

Preparedness: injection well system, shoreline protection works, enhanced capacity of drainage network, updated water resources management plan

Egyptian coastline is continuously monitored and protected where needed with hard structure measures. Also, with historical experience and major river, the River Nile, Egypt is considered well-equipped with hydraulic and hydrologic consultants with reasonable background in dealing with hydro-physical difficulties.

\section{Social equation}

Threats: damaged housing and infrastructure, migratory action ( moving the problem to another place) loss of job opportunities hence increased unemployment rate, limitation in resources

Preparedness: precautionary measures, raised awareness, higher education

Seasonality of employment is a major trend in the study area, and directly related to climate status (tourism, agricultural and fishing activities) which increases the risk with changes in climate to elevated poverty, unemployment and food security concerns. In addition, population with working age (15-60) are about $63.75 \%$ of total population (IGSR, 2010). While this high percentage of working power raise demand concerns for job opportunities, it could also be considered available power if equipped with capacity building and marketoriented skills

\section{Economic \&Investments equation}

Threats: loss of industrial facilities, agricultural lands, tourism resorts

Preparedness: coastal protection measures in place, planning ahead pre-construction to elevated foundation than expected sea level rise and groundwater table, disseminate information and raise awareness among stakeholders about consequences and possible measures to avoid and/or alleviate losses.

The task of maintaining a functional system, and balancing the equation with adjustability versus changes, required addressing these three equations simultaneously, while combining the technical expertise with socio-economic contexts and creating a bridge between the science community and civil society, figure (2). The scheme was to cover all components starting from raising awareness of simple communities to arming the researchers with advanced techniques.

Participation of civil society representatives from all walks of life; Businessmen and investors, governorate Secretary General, fishermen, farmers, City Council employees, housewives, and even school children has started from the initial steps of the research project. First, field surveys, semi-structured meeting 
and workshops have been held to evaluate the basic information of different categories in the community on climate change phenomenon, understanding the characteristics of the communities located in the study area, and assessing the needs and vulnerabilities of these communities most likely to be affected by Sea Level Rise. This covered the demographics of the communities, availability of infrastructure, accessibility to services, types of economic activities and livelihoods, environmental conditions; and perceptions of climate change, followed by awareness raising and deliberation of actual scientific facts.

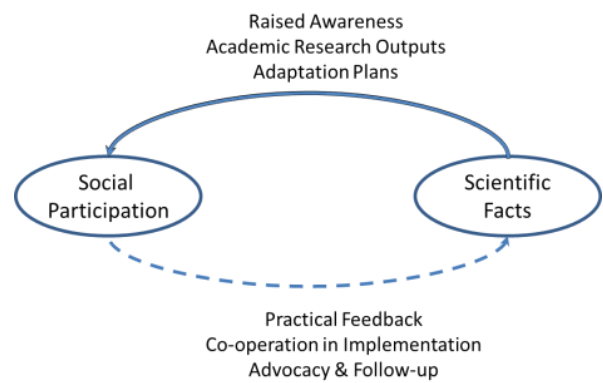

Figure 2: Interactive process in planning for climate change adaptation

Throughout the research project steps, there have been regular meeting conducted with community groups and representative of stakeholders, flowchart of applied activity sequence is shown in Figure 3. The last phase of the interactive scheme has been with prediction outcomes and proposed adaptation options. The main purposes of the conducted meetings have been to inform the community parties of what scientific researches concluded and get their feedback of proposed adaptation options. These meetings have been considered a winwin gathering opportunity that feed those with scientific background with responses of people well-experienced with their local environment. Meanwhile, informing local societies with detailed reasoning of concluded solution would ensure their advocacy and cooperation during implementation phase.

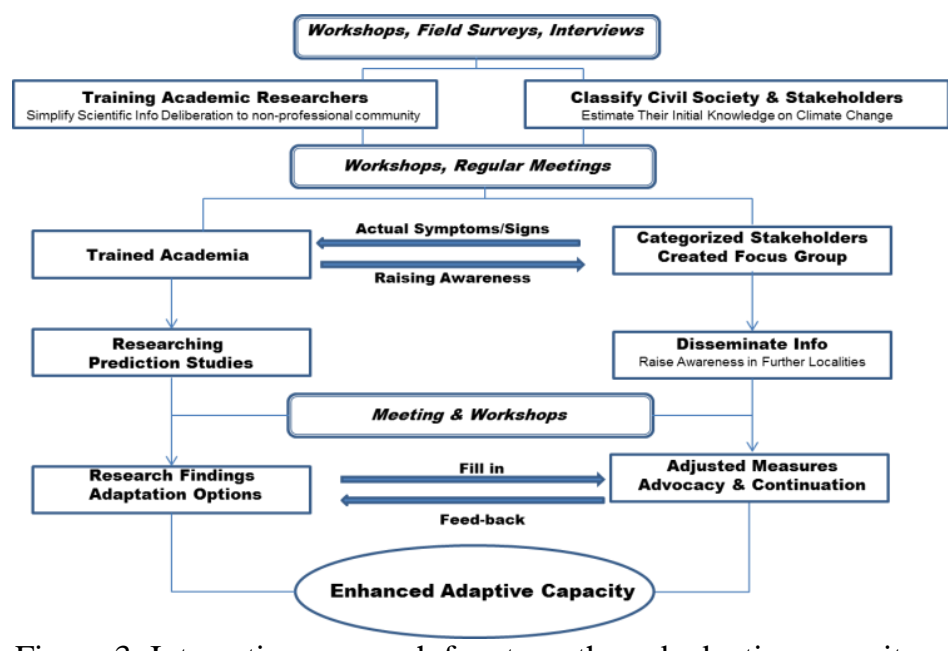

Figure 3: Interactive approach for strengthened adaptive capacity

\section{Discussion}

Evidently, impact of predicted Sea Level Rise would go beyond inundating parts of the region adjacent to the shoreline. Advancing saltwater/freshwater interface, elevating groundwater levels as well as increasing ambient salinity degree are among major concerns to address. Implied concerns of Sea Level Rise on coastal zone can be summarized as:

- Vulnerability to inundation of Lowland, tourism resorts and infrastructure

- Advancement of saltwater/freshwater interface inland within the aquifer

- Saltwater intrusion and potential elevated salinity in water and soil

- Shortage in fresh groundwater availability for beneficial uses

- Elevation in groundwater levels

- Concerns on agricultural land productivity and pressure on drainage systems

- Impact on natural resources, fisheries and ecosystem sustainability

- Impact on development process and socio-economic activities, and safety of populated areas 
Technical research studies of physical and hydrological state highlighted system vulnerability in forms of; shoreline advancement and land inundation, saltwater intrusion into coastal aquifer, and drainage water exceedance than assimilative capacity of the present network. Recommended adaptation measures showed tendency to apply hard engineering structures for shoreline protection. Furthermore, required improvements for upgrading the drainage network and increasing its capacity have been concluded. In order for alleviating saltwater intrusion into the coastal aquifer within the study area, adaptation practice has been recommended.

In this context, adaptive capacity can be considered acceptable with existing expertise in the field of hydrological/hydraulic practices in Egypt. However, certain limitation in advanced technology has been detected, which would have an adverse impact in capacity to accurately follow changes and predict scenarios, and hence reach applicable solutions for adaptation to climate change.

With regard to the social stability and economic prosperity in face of climate change impact, surveys, activities and research studies conducted within the project framework have shown wide range of economic, professional and educational background. Also presented in these studies is the demographic distribution and predicted alterations in land-uses. As argued in literature, the adaptive capacity has indicators directly related to factors such as education, income and health, as well as institution and technology abilities (Yohe and Tol, 2002; Downing, 2003; Brooks et al., 2005; Tol and Yohe, 2007).

Present a policy of adaptive capacity based on scientific facts, while bearing human dimension (knowledge, raised awareness, built capacity), and armed with technical tools and reliable monitoring ensure more enhanced capacity to adapt to climate change. However, while examining adaptive capacity; other aspects are of importance to include, such as preparedness of decision makers to adopt more flexible planning methodology, tendency of civil society to actively cooperate with proposed adaptation measures, and media negative/positive role in shaping reflections. Media could encourage community involvement, and deliver trustful scientifically- based research results. Yet, on the other hand, media can be played with and create unneeded panic, false alarming situation with vague information that, in turn, would flip the coin.

\section{Conclusion \& Recommendations}

The integrated research study has covered bio-physical aspects of projected climate change impact while emphasizing the importance of involving the relevant authorities, stakeholders and community groups in its research and activities. Social participation was a cross-cutting objective throughout the research project and, thus, every sector is expected to play a role in facing the likely impact of the Sea Level Rise and enhance the socio-economic advocacy, cooperation and eventually the adaptive capacity.

A broad view of physical preparedness of the coastal zone to predicted Sea Level Rise (e.g. shoreline protection measures already in place, capacity of the drainage network system, pressure on the coastal aquifer...etc.) has been used as a guide in evaluating adaptive capacity. Accordingly, planning for further management measures are recommended where needed. Meanwhile, the socio-economic adaptive capacity has been examined in terms of sectors of civil society, stakeholders and decision makers' response.

The project results show how promising is the mixture between firm scientific facts with actual interaction with civil society and stakeholders, in transferring important knowledge to the community, on one hand, and assimilating their feedback in management plans, on the other. This process, consequently, enhance the adaptive capacity in face of predicted impact of climate change. However, experience during the research progress showed how hard the initial step in working with the community in such a matter. Yet responses and positivity in reacting were found varying with different education and economic background. It can be concluded that education level and secured economic standard or comfortable standard of living play an important role in having positive cooperative attitude from the communities, an issue to be accounted for in evaluating adaptive capacity.

In Conclusion, changes are inevitable and should be prepared for in advance to alleviate losses. It is better be away from threshold than barely keeping our nose above the water. Having the capacity to adapt proved directly related to the capability to be more flexible to changes while armed with required tools. The adaptive capacity also proved an essential key for the design and implementation of effective adaptation strategies so as to reduce the likelihood and the magnitude of harmful outcomes resulting from climate change (Brooks and Adger, 2005).

To enhance adaptive capacity, it is recommended to have:

Firm institutional structure that is responsive and consider the needs of all concerned parties as well as environmental sustainability

Flexible/reflective/adjustable planning scheme with cooperative decision makers

(Flexibility in planning and allocated budget as need arise/ free hand and looser limits, obviously with regular consultation and revision)

Plan for capacity building and expertise exchange

Keep updated with advances in modeling techniques 
Strengthened Adaptive Capacity Using Interactive Approach Integrative Framework: Science

Finally, it is recommended to ensure maintained involvement of different beneficiaries/stakeholders, keep them informed with established message transfer mechanism, updating information and consider their feedback.

\section{References}

[1]. Brooks, N. and W.N. Adger 2005, Assessing and enhancing adaptive capacity. Adaptation Policy Frameworks for Climate Change, B. Lim, E. Spanger-Siegfried, I. Burton, E.L. Malone and S. Huq, Eds., Cambridge University Press, New York, Pp. 165-182.

[2]. Brooks, N., W.N. Adger and P.M. Kelly, 2005, The determinants of vulnerability and adaptive capacity at the national level and the implications for adaptation. Global Environ. Change, 15, Pp. 151-163.

[3]. Buss, D.M. and Greiling, H. 1999. Adaptive individual differences. Journal of Personality, 67: 209-243.

[4]. Douglas, B. 1997, Global Sea Rise: A Redetermination, Surveys in Geophysics, Volume 18, Numbers 2-3, Pp. 279-292

[5]. Downing, T. 2003, Toward a vulnerability/adaptation science: lessons from famine early warning and food security. Climate Change Adaptive Capacity and Development, J.B. Smith, R.J.T. Klein and S. Huq, Eds., Imperial College Press, London, Pp. 77100 .

[6]. Institute of Graduate Studies and Research (IGSR) 2010, Population and Land Use Long Term projection, Project of adaptation to the impacts of sea level rise in the Nile Delta coastal zone, Egypt, report 3

[7]. Intergovernmental Panel on Climate Change (IPCC), 2007, Fourth Assessment Report on Climate Change, Working Group II: Impacts, Adaptation and Vulnerability

[8]. Starr and Taggart 2004, Ecology and Behavior from Biology: The Unity and Diversity of Life 10th edition, Thompson publishers ISBN 0-534-39746-8

[9]. Tol, R.S.J. and G.W. Yohe 2007, The weakest link hypothesis for adaptive capacity: An empirical test. Global Environ. Chang., 17, Pp. 218-227.

[10]. Yohe, G. and R.S.J. Tol 2002, Indicators for social and economic coping capacity - moving toward a working definition of adaptive capacity. Global Environ. Change, 12, Pp. 25-40. 